\section{Repair of double-chambered right ventricle using right ventricular outflow chamber ventriculotomy via left intercostal thoracotomy under beating heart in two dogs}

Keiichi Sato, 1 Isamu Kanemoto, 1 Kippei Mihara, ${ }^{1}$ Koudai Kawase, 1 Takuya Mori, 1 Misato Ohashi, 1 Hirokazu Abe, ${ }^{1}$ Shuichi Chimura²

1Chayagasaka Animal Hospital, Nagoya, Aichi; ${ }^{2}$ Chimura Animal Hospital, Iwakura, Aichi, Japan

\section{Abstract}

Double-chambered right ventricle was diagnosed in two dogs, one of them a pup and the other full grown. Both dogs underwent surgery using the novel approach of right ventricular outflow chamber ventriculotomy via left intercostal thoracotomy with moderate hypothermia and moderate pump flow cardiopulmonary bypass under beating heart. No major complication occurred during and after the operation. On continuous wave Doppler echocardiography, the pressure gradient across the stenosis in the right ventricle decreased from 130 $\mathrm{mmHg}$ pre-operatively to $40 \mathrm{mmHg}$ post-operatively at 1 year 5 months in the adult dog, and from $209 \mathrm{mmHg}$ pre-operatively to $47 \mathrm{mmHg}$ post-operatively at 1 year in the pup. Both dogs are active without clinical signs.

\section{Introduction}

Double-chambered right ventricle (DCRV) is a relatively uncommon congenital cardiac abnormality in dogs. ${ }^{1}$ The right ventricle (RV) is divided into two compartments by an anomalous muscular bundle and is composed of an inflow high pressure chamber and an outflow low pressure chamber. ${ }^{2-4}$

In human, DCRV usually is associated with thickening of the inflow RV wall induced by pressure overload and the pressure gradient across the RV stenosis caused by the abnormal muscular bundle worsens with time. If the pressure gradient across the stenosis in $\mathrm{RV}$ is $>30 \sim 50 \mathrm{mmHg}$, surgical correction of the abnormality is recommended regardless of the age at diagnosis.5,6 Various surgical techniques for removing the anomalous muscular bundle have been applied in humans (e.g. through a right atriotomy, a right ventriculotomy or a combined transatrial-transpulmonary approach with cardiopulmonary bypass (CPB). ${ }^{7-9}$ In veterinary literature, there are a few reports of DCRV surgical correction in dogs, ${ }^{10-12}$ and the surgical procedure for it is still not established.

This report describes the successful correction of DCRV in two dogs through the new RV outflow chamber (RVOC) approach under beating heart.

\section{Case Report}

Case 1 was a female miniature dachshund weighing $6.48 \mathrm{~kg}, 1$ year and 10 months old, which presented with repeated syncope on excitation and a heart murmur. Case 2 was a flat-coated retriever, female, weighing $8.78 \mathrm{~kg}$, 84 days old, which presented with hind limb unstable gait and a heart murmur.

Auscultation revealed a 4/6 systolic ejection murmur in case 1 , and a $5 / 6$ systolic ejection murmur in case 2 at the left precordial region.

Electrocardiogram and thoracic X-ray examinations suggested RV enlargement in both cases.

Echocardiography revealed a severe fixed stenosis of the RV lumen due to an abnormal bundle, which divided the RV into two chambers and mild and moderate tricuspid regurgitation (TR) was present in case 1 and 2, respectively. Also a persistent left anterior vena cava (PLAVC) was seen in both cases. Additionally, a right-to-left shunting flow was seen through a small membranous ventricular septal defect (VSD) in case 2. Continuous wave Doppler showed a pressure gradient of $130 \mathrm{mmHg}$ across the stenosis in case 1 and a pressure gradient of $209 \mathrm{mmHg}$ in case 2 (Figure 1).

Nonselective cardiac angiography revealed a fixed obstruction of the RV lumen separating it into two compartments and a normal pulmonary valve and arteries in both cases.

Anesthesia, cardiopulmonary bypass: surface-induced moderate hypothermia (esophageal temperature $25-28^{\circ} \mathrm{C}$ ) with moderate pump flow $(60-80 \mathrm{~mL} / \mathrm{kg} / \mathrm{min}) \mathrm{CPB}$ was used under beating heart.13 Dogs were premedicated with acepromazine $(0.05 \mathrm{mg} / \mathrm{kg}$ SC), atropine $(0.025 \mathrm{mg} / \mathrm{kg}, \mathrm{SC})$, and hydroxyzine $(1 \mathrm{mg} / \mathrm{kg} \mathrm{SC})$ at 30 minutes, and fentanyl $(2.5 \mathrm{~g} / \mathrm{kg} \mathrm{IV})$ at 15 minutes before induction. Anesthesia was induced with thiamylal (12.5 $\mathrm{mg} / \mathrm{kg} \mathrm{IV}$ ), and maintained with inhalation of isoflurane and intermittent administration of pancronium $(0.06 \mathrm{mg} / \mathrm{kg} \mathrm{IV})$. After administration of heparin (400 IU/kg IV), a venous cannula was inserted from the left jugular vein into the right atrium and an arterial cannula was inserted through the left carotid artery toward the heart. An additional large venous cannula was inserted from the right atrial appendage
Correspondence: Isamu Kanemoto, Chayagasaka Animal Hospital, 1-1-5 Shinnishi, Chikusa Nagoya, Aichi, 464-0003 Japan.

Tel. +81.527.731.866 - Fax: +81.527.737.488

E-mail: kanemoto@ta2.so-net.ne.jp

Key words: dog, double-chambered right ventricle, surgical repair, beating heart, cardiopulmonary bypass.

Contributions: the authors contributed equally.

Conference presentation: part of this paper was presented at the 38th Annual Congress of Word Small Animal Veterinary Association, from March 6-9, 2013, in Auckland, New Zealand.

Received for publication: 9 April 2014. Accepted for publication: 7 May 2014.

This work is licensed under a Creative Commons Attribution NonCommercial 3.0 License (CC BYNC 3.0).

(C) Copyright K. Sato et al., 2014

Licensee PAGEPress srl, Italy

Veterinary Science Development 2014; 4:5425 doi:10.4081/vsd.2014.5425

into the right atrium after left thoracotomy. The right femoral artery and vein were cannulated for monitoring arterial blood pressure and blood gases and for central venous pressure, respectively.

Surgical method: the left $4^{\text {th }}$ intercostal thoracotomy was used. The pericardium was cut in a T-shape under the phrenic nerve, and the ventral sides were secured with sutures to the sternum to expose the RV outflow tract (RVOT). The RV outflow chamber was incised and the stenotic hole was measured with a sizer. The stenotic ring was cut free from the RVOC toward the RV inflow chamber (RVIC) through the stenotic hole and the stenotic dividing wall was removed with scissors (Figure 2). During the repair, a suction tube was inserted toward RVIC for a good surgical view. Stenotic opening size was enlarged from $4 \mathrm{~mm}$ to $11 \mathrm{~mm}$ in case 1 , and from $5 \mathrm{~mm}$ to 8 $\mathrm{mm}$ in case 2 . The RV incision was sutured directly with double continuous sutures using Proline 5-0 suture attached pledgets. In both dogs ventricular fibrillation (Vf) did not occur during the repair. The chests were closed routinely.

Postoperative course: Although a grade $3 / 6$ systolic murmur remained after operation, clinical signs disappeared completely in both cases. Case 1 was discharged from our hospital at 4 days, and case 2 at 7 days after operation. On postoperative color Doppler echocardiography, a small left-right shunt VSD was newly discovered in case 1 and a right-left shunt VSD changed to a left-right shunt in case 2 . Continuous wave 
Doppler showed that the pressure gradient across the stenosis was decreased from 130 $\mathrm{mmHg}$ pre-operatively to $6 \mathrm{mmHg}$ at 3 months, and increased to $40 \mathrm{mmHg}$ at 1 year 5 months post-operatively following previous discontinuation of atenolol by the owner at 3 months postoperatively in case 1 . In case 2 the pressure gradient decreased from $209 \mathrm{mmHg}$ to $35 \mathrm{mmHg}$ at 3 months and increased to $47 \mathrm{mmHg}$ at 1 year post-operatively, continuing treatment with atenolol (Table 1). As shown in Table 1 continuous wave Doppler showed that the pressure gradient across the stenosis was decreased from $130 \mathrm{mmHg}$ preoperatively to $6 \mathrm{mmHg}$ at 3 months, since which the owner canceled the administration of a $\beta$-blocker drug (atenolol) and increased to $40 \mathrm{mmHg}$ at 1 year 5 months after operation in case 1 , and from $209 \mathrm{mmHg}$ to $35 \mathrm{mmHg}$ at 3 months and increased to 47 $\mathrm{mmHg}$ at 1 year after operation in case 2 , continuing to administer the drug from first to the present.

\section{Discussion and Conclusions}

All surgical repair reports of DCRV in the dog used RVOT ventriculotomy via the right intercostal thoracotomy or the median sternotomy. ${ }^{10}$
13 They approached the stenotic lesion from the RVIC. In contrast, although we used the same RVOT ventriculotomy, we approached the stenotic lesion from the RVOC via the left $4^{\text {th }}$ intercostal thoracotomy. The advantages of the RVIC approach are the ability to repair a possible tricuspid valve anomaly combined with the DCRV. The disadvantages of this technique are the difficulty in confirming and resecting the stenotic lesion of the RVOT because the RVOT is located in the dorsal position of the heart and RVIC is narrowed due to the hypertrophied RV wall, papillary muscles and chordae. As a result, there would be a greater risk of injuring the tricuspid valve apparatus or more difficulty in sufficiently removing the stenotic lesion even under cardiac arrest. In contrast, the RVOC technique makes it relatively easy to confirm the stenotic hole, to check the size and resect the stenotic lesion, because the RVOT is located under direct vision in the left $4^{\text {th }}$ intercostal thoracotomy and the RVOC is relatively wide due to no hypertrophied RV wall and no interruption except for the stenotic ring. The RVOC technique described here allowed the successful repair of the DCRV under the beating heart in small sized dogs, and provides evidence for its potential usefulness for the correction of this cardiac anomaly in these patients. One disadvantage of the RVOC technique is that it does not allow correction of concurrent tricuspid valve anomaly. However, there is no report of TV anomaly repair concurrently with DCRV in dog.

From the viewpoint of myocardial preservation, Martin operated on DCRV under beating heart in two of 7 dogs; 11 however, Vf occurred during the repair in both dogs. Neither of our dogs had Vf under beating heart with moderate hypothermia and moderate pump flow CPB because both techniques appropriately satisfied myocardial oxygen supply and demand for myocardial preservation. 14

Air embolism was avoided because the R-to$\mathrm{L}$ shunt before the release of the stenotic lesion changed instantaneously to the L-to-R shunt after the release of the stenotic lesion under the beating heart in our case. When a large VSD exists and the RVIC approach is used under beating heart, there is a risk of air embolism.

On echocardiography, the pressure gradient across the stenosis was diminished from 130 $\mathrm{mmHg}$ pre-operatively to $40 \mathrm{mmHg}$ post-operatively at 1 year 5 months in case 1 , and from $209 \mathrm{mmHg}$ pre-operatively to $47 \mathrm{mmHg}$ postoperatively at 1 year in case 2 (Table 1). At present both dogs are active without clinical signs and the pressure gradients of $<50 \mathrm{mmHg}$ seems to be within the acceptable range at midterm results. However, long-term follow-up

Table 1. Comparison of preoperative and postoperative pressure gradient across the stenosis in both cases.

\begin{tabular}{ccccccc} 
Case & Pre-op & $\begin{array}{c}\text { Post-op } \\
1 \text { month }\end{array}$ & $\begin{array}{c}\text { Post-op } \\
3 \text { months }\end{array}$ & $\begin{array}{c}\text { Post-op } \\
8 \text { months }\end{array}$ & $\begin{array}{c}\text { Post-op } \\
12 \text { months }\end{array}$ \\
1 & 130 & 48 & 6 & 19 & - & 40 \\
2 & 209 & 58 & 35 & 41 & 47 & - \\
\hline
\end{tabular}

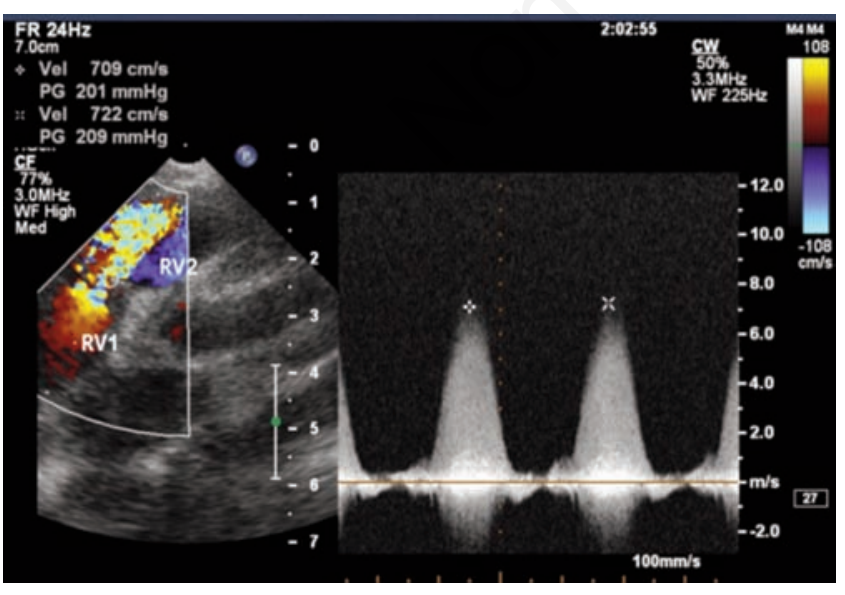

Figure 1. Echocardiography of right outflow tract (left parasternal oblique short-axis view at basal level) and continuous Doppler in case 2. In the left figure, severe stenosis separates the RV into two chambers (RV1 and RV2) and causes mosaic blood flow in the right ventricle. In the right figure, the Doppler shows maximum blood-flow speed at stenosis of $7.2 \mathrm{~m} / \mathrm{sec}$, corresponding to the pressure gradient of $209 \mathrm{mmHg}$.
A
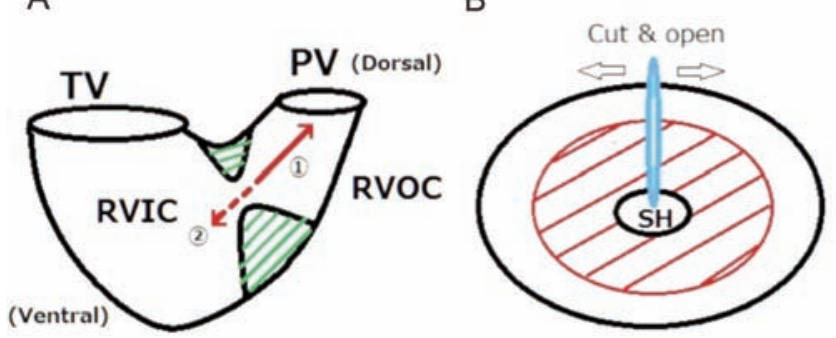

Figure 2. Surgical diagram of RV outflow ventriculotomy: surgeon stands and approaches the surgical field from dorsal side of the dog. First, the RV outflow chamber (RVOC) was incised with a scalpel (solid line 1 in the left figure A) and the stenotic hole (SH) size was measured with a sizer. Then, the stenotic ring was cut at the dorsal portion from RVOC toward the RV inflow chamber (RVIC) (dotted line 2 in the left $A$ and vertical line in the right $B$ figures), and the stenotic dividing wall was removed with scissors (oblique line area in the right figures $B$ showing surgeon view). TV: tricuspid valve; PV: pulmonary valve 
should be considered because of restenosis. Also, the dog operated for DCRV should be administered the $\beta$-blocker drug to prevent the restenosis or be combined with the RVOC technique and patch technique in large sized dogs, especially in young dogs during periods of growth. ${ }^{11}$ Our novel surgical technique for DCRV may be useful in a low-body weight small dog.

\section{References}

1. Buchanan JW. Prevalence of cardiovascular disorders. In: Fox PR, Sisson D, Moise NS, eds. Textbook of canine and feline cardiology: principles and clinical practice. 2nd ed. Philadelphia: WB Saunders; 1999. pp 457-470.

2. Morozumi M, Kurosu Y, Kogure K, et al. Double-chambered right ventricle, ventricular septal defect, patent ductus arteriosus in a dog. Adv Anim Cardiol 1989;22:36-43.
3. Koie H, Kurotobi EH, Sakai T. Doublechambered right ventricle in a dog. $\mathrm{J}$ Vet Med Sci 2000;62:651-3.

4. Fukushima R, Tanaka R, Suzuki S, et al. Epidemiological and morphological studies of double-chambered right ventricle in dogs. J Vet Med Sci 2011;73:1287-93.

5. Gatai 0, Al-Halees Z, Solymar L, et al. Double-chambered right ventricle in 73 patients: spectrum of the disease and surgical results of transatrial repair. Can $\mathrm{J}$ Cardiol 2000;16:167-74.

6. McElhinney DB, Chatterjee KM, Reddy VM. Double-chambered right ventricle presenting in adulthood. Ann Thorac Surg 2000; 70:124-7.

7. Penkoske PA, Duncan N, Collins-Nakai RL. Surgical repair of double-chambered right ventricle with or without ventriculotomy. J Thorac Cardiovasc Surg 1987;93:385-93.

8. Hachiro H, Takagi N, Koyanagi T, et al. Repair of double-chambered right ventricle: surgical results and long-term followup. Ann Thorac Surg 2001;72:1520-2.

9. Said SM, Burkhart HM, Dearani JA, et al.
Outcomes of surgical repair of doublechambered right ventricle. Ann Thorac Surg 2012;93:197-200.

10. Willard MD, Eyster GE. Double-chambered right ventricle in two dogs. J Am Vet Med Assoc 1981;178:486-8.

11. Martin JM, Orton EC, Boon JA, et al. Surgical correction of double-chambered right ventricle in dogs. J Am Vet Med Assoc 2002;220:770-4.

12. Tanaka R, Shimizu M, Hirano H, et al. Surgical management of a double-chambered right ventricle and chylothorax in a Labrador retriever. J Small Anim Prac 2006;47:405-8.

13. Kanemoto I, Taguchi D, Yokoyama S, et al. Open heart surgery with deep hypothermia and cardiopulmonary bypass in small and toy dogs. Vet Surg 2010;39:674-9.

14. Song J, Liang Y, Li A, et al. Experimental study of myocardial protective effect of cardiac arrest versus beating heart during open heart surgery. Chin Critic Care Med 2003;15:288-91. 